\title{
Quais teorias e métodos para a pesquisa sobre o ensino da matemática?*
}

\author{
What are the theories and methods guiding \\ research on the teaching of mathematics?
}

\section{Quelles théories et quelles méthodes pour les recherches sur l'enseignement des mathématiques?}

\author{
Raymond Duval $^{* *}$
}

\begin{abstract}
Resumo: A matemática provoca dificuldades de compreensão que não são encontradas em outras disciplinas. A escolha de uma teoria e de um método para recolher e analisar os trabalhos dos alunos depende do ponto de vista do qual nós nos baseamos para estudá-los. Neste artigo, examinaremos e faremos uma comparação dos aportes específicos dos pontos de vista matemático, cognitivo e pedagógico para analisar os processos de compreensão e de aquisição de conhecimentos em matemática. Com este objetivo abordaremos quatro questões: a) os critérios de compreensão são os mesmos segundo estes três pontos de vista?; b) o sucesso matemático em um problema implica a compreensão de um ponto de vista cognitivo?; c) como distinguir tipos de erros para analisar as causas de incompreensão?; d) as progressões construídas a partir de análises em termos de "pré-requisitos" favorecem ou ignoram o desenvolvimento cognitivo específico que permite compreender em matemática? Nós mostraremos que a importância particular do ponto de vista cognitivo vem do fato de que a atividade matemática tem sempre duas faces.
\end{abstract}

Palavras-chaves: Critério de compreensão. Decomposição de um conhecimento. Reconhecimento.

\begin{abstract}
Mathematics presents some difficulties of comprehension which are not found in other subjects. The choice of theories and methods to collect and analyze students' work depends on the perspective taken to study them. This paper examines and compares the mathematical, cognitive and pedagogical perspectives to analyze the process of comprehension and acquisition of mathematical knowledge. With this aim, four issues are approached: a) are the comprehension criteria the same under the three perspectives?; b) does mathematical success with a problem mean comprehension of a cognitive viewpoint?; c) how can types of error be distinguished in order to analyze the causes of lack of comprehension?; d) do progressions built on "pre-requisite" analyses
\end{abstract}

\footnotetext{
* Tradução de Luciana da Costa Oliveira, com revisão técnica do Prof. Dr. Méricles T. Moretti.

** Professor Emérito da Université du Littoral Côte d’Opale/França. E-mail: <duval.ray@wanadoo.fr>
} 
favor or ignore the specific cognitive development which leads to the comprehension of mathematics? The paper shows that the particular importance of the cognitive perspective stems from the fact that the mathematical activity has always two sides.

Keywords: Criterion for comprehension. Decomposition of knowledge. Recognition.

Resumé: Les mathématiques soulèvent des difficultés de compréhension qu'on ne retrouve pas dans les autres les autres disciplines. Les choix d'une théorie et d'une méthode pour recueillir et analyser les productions des élèves dépendent du point de vue auquel on se place pour les étudier. Dans cet article nous examinerons et comparerons l'apport spécifique des points de vue mathématique, cognitif et pédagogique pour analyser les processus de compréhension et d'acquisition de connaissances en mathématiques. Dans ce but nous aborderons quatre questions: a) les critères de compréhension sontils les mêmes selon ces trois points de vue?; b) la réussite mathématique à un problème implique-t-elle la compréhension d'un point de vue cognitif?; c) comment distinguer des types d'erreurs pour analyser les causes d'incompréhension?; d) les progressions construites à partir d'analyses en termes de «prérequis» favorisent-elles ou ignorent-elles le développement cognitif spécifique qui permet de comprendre en mathématiques? Nous montrerons que l'importance particulière du point de vue cognitif vient $\mathrm{du}$ fait que l'activité mathématique a toujours deux faces.

Mots clés: Critères de compréhension. Décomposition d'une connaissance. Reconnaissance.

\section{Introdução}

Esta questão pode parecer ingênua ou deslocada, porque as pesquisas sobre o ensino da matemática são atualmente uma especialidade acadêmica bem identificada e diretamente ligada à formação dos professores. Porém ela se impõe, uma vez que o campo de pesquisas é vasto e diverso. Em primeiro lugar, existe a heterogeneidade dos grupos de alunos aos quais o professor de matemática se dirige: todos os alunos do Ensino Fundamental ao Ensino Médio; em seguida os subgrupos de estudantes que seguem áreas científicas ou técnicas. Existe uma diversidade de áreas, nas quais é necessário transmitir experiências adquiridas: os números, a geometria, a análise, a álgebra, as estatísticas, etc. Existe, também, a renovação dos métodos ou dos instrumentos didáticos, como, por exemplo, a utilização da informática. Existe a evolução das expectativas sociais em termos de formação dos indivíduos, aos quais as reformas sucessivas dos programas tentam atender.

O campo das pesquisas sobre o ensino da matemática é, portanto, muito fragmentado. $\mathrm{O}$ que pode existir em comum entre pesquisas sobre as atividades numéricas ou sobre a geometria no Ensino Fundamental, pesquisas sobre a introdução da álgebra ou sobre a exigência das "provas" no Ensino Fundamental, pesquisas sobre a análise ou sobre a álgebra linear na universidade? Os perfis 
de alunos não são os mesmos do ponto de vista do nível de desenvolvimento intelectual e das orientações de futuro próximo ou longínquo, pois em todos os casos fazem "matemática" resolvendo problemas que mostrariam a utilidade prática ou o interesse estético das matemáticas. Mas isto não estabelece nenhum consenso entre aqueles cujos trabalhos baseiam-se em conteúdos matemáticos que são diferentes, que são ensinados a grupos diferentes e com objetivos de formação diferentes. Qual é então o domínio de validade das “teorias” às quais a pergunta se refere? Fica este domínio restrito ao campo particular de pesquisa para o qual esta ou aquela teoria foi, de início, elaborada, ou ele pode se expandir a todos os níveis do ensino da matemática? Uma teoria pode mesmo englobar todos os pontos de vistas que se podem ter sobre a organização do ensino e sobre a escolha de seus conteúdos?

Para apreender a razão profunda e o objeto das pesquisas em didática, é necessário lembrar as duas mudanças que criaram a situação radicalmente nova na qual o ensino da matemática se encontra atualmente. De início, houve aquilo que então se chamou a "massificação do Ensino Fundamental", com a abertura de um mesmo programa de estudos para todos os alunos até dezesseis anos. Houve a necessidade de uma outra abordagem matemática dos conteúdos ensinados para uma pedagogia mais ativa e, ao mesmo tempo, para a adaptação a um contexto tecnológico que exigia mais conhecimento matemáticos. Isto fez surgir a urgência de uma questão que, até este momento, não existia nesta escala demográfica e sob a pressão cultural de uma "alfabetização matemática": por que a matemática provoca dificuldades de aprendizado que não são encontradas em outras disciplinas e por que estas dificuldades se mostram insuperáveis para muitos alunos? Esta questão das dificuldades específicas no aprendizado da matemática constitui, evidentemente, o maior desafio do professor. Ela se encontra em todos os níveis do currículo. Respondê-la é o maior objetivo das pesquisas sobre o ensino, uma vez que ela se relaciona com a compreensão e com a capacidade de utilização da matemática pelos alunos. Mas como? É aí que se encontra nossa pergunta inicial sobre as teorias e os métodos exigidos para conduzir estas pesquisas.

Para descrever os processos de compreensão é necessário importar teorias cognitivas mais gerais como se fez com o modelo construtivista de Piaget, como se fez mais recentemente com a semiótica de Peirce e como se começa a fazer pelo ângulo das neurociências? Ou, ao contrário, é necessário privilegiar o estudo epistemológico da construção dos objetos ou das noções matemáticas e a pesquisa dos tipos de problemas que conduziram ao desenvolvimento deles? Em outras palavras, qualquer que seja a teoria que se escolha, é necessário questionar, por um lado, sobre sua pertinência em relação aos problemas específicos de compreensão que o aprendizado da matemática provoca e, por outro lado, sobre seu domínio de validade. Para 
o caso no qual a teoria é pertinente, ela é válida somente para alguns conteúdos matemáticos, para um nível de ensino ou ela se aplica às diferentes áreas da matemática e aos diferentes níveis de ensino?

Para analisar os fenômenos de compreensão e de aquisição de conhecimentos pelos alunos, é necessário privilegiar métodos relativos aos dados qualitativos colhidos "em campo" durante o trabalho em classe? Ou, ao contrário, é necessário privilegiar métodos relativos a dados quantitativos, baseados nos desempenhos e nas respostas matemáticas dos alunos ao final de uma sequência de aprendizado? Em outras palavras, quaisquer que sejam o método e o tipo de dados escolhidos, é necessário se perguntar sobre os critérios obtidos na análise dos trabalhos dos alunos para determinar um indicador de compreensão ou uma real aquisição que possa ser utilizada posteriormente em outros contextos. A validade dos resultados e a confiança na interpretação destes resultados dependem da escolha dos critérios de compreensão assim como do nível de reagrupamento dos elementos que a análise dos trabalhos nos leva a distinguir. O que se trata de avaliar aqui não é somente a aceitação de um resultado, mas sua contribuição e a possibilidade de sua utilização em outros trabalhos. Esta é a condição de um progresso real nas pesquisas sobre o ensino da matemática.

São todas estas questões que vamos retomar e desenvolver neste artigo. Elas mostram a complexidade particular, muito frequentemente subestimada, das pesquisas sobre o ensino da matemática. Esta complexidade está ligada ao fato de que este campo de pesquisas provoca vários pontos de vista totalmente diferentes e que não devem jamais ser confundidos: ponto de vista matemático, ponto de vista epistemológico, ponto de vista cognitivo, ponto de vista dos alunos, ponto de vista dos professores, ponto de vista institucional, etc. Isto se deve ao fato de que os fenômenos observados e os problemas a explorar estão longe de ser os mesmos dependendo do ponto de vista do qual são observados. Este é o ponto ainda não atingido pela maioria das pesquisas, isto é: a relação entre estes diferentes pontos de vista. Existe um ponto de vista que seja central e superior aos outros ou que os englobe? Ou, ao contrário, certos pontos de vista são igualmente importantes e, até mesmo, localmente incompatíveis em relação aos outros?

Vamos retomar todas estas questões observando uma ordem inversa daquela que é classicamente exigida para a submissão de um artigo para um congresso, de um artigo para uma revista e para a redação de memorial ou de uma tese. Começaremos pela questão dos critérios de compreensão em matemática e mostraremos que existem dois pontos de vista essenciais e igualmente irredutíveis: o ponto de vista matemático e o ponto de vista cognitivo. Realçaremos que o ponto de vista cognitivo é irredutível em relação ao ponto de vista psicológico ou pedagógico, porque se deve considerar a situação epistemológica do modo de 
acesso aos objetos matemáticos. Em seguida, abordaremos a questão metodológica da análise e da interpretação dos trabalhos dos alunos. Esta análise exige uma dupla codificação. Veremos os problemas específicos que isto suscita. O primeiro está relacionado à possibilidade ou não de interpretar os sucessos no que diz respeito à compreensão ou aquisição de um conhecimento pelos alunos. O segundo relaciona-se à necessidade de nunca confundir dois tipos de erros que são radicalmente diferentes, tanto no plano da observação quanto no plano das razões manifestadas de incompreensão. Enfim, abordaremos a questão da escolha de uma teoria que, lamentavelmente, se destaca em demasia nas pesquisas ou na formação para a pesquisa! Nós veremos que uma teoria é sempre ligada a um ponto de vista e a um só, mesmo que este ponto de vista deva sempre se articular com o ponto de vista matemático.

\section{O que se deve compreender em matemática? Pontos de vista cognitivo e matemático}

Na matemática, mais que em todas as outras disciplinas, é necessário compreender para poder aprender. Somente se pode aprender matemática e concluir as atividades propostas se compreendermos não somente as instruções e os enunciados de um problema, mas também aquilo que se pode fazer para buscar resolvê-lo e por que aquilo que se encontra está certo ou errado. A repetição sem reflexão não gera nenhuma aquisição real e útil. Isto se deve a que utilizar este procedimento ou considerar explicações advindas dele conduz frequentemente a resultados errôneos e confusos que mostram que "não se entendeu", ou que o conhecimento subjacente não foi adquirido. Esta exigência constante de compreensão coloca o ensino da matemática em uma situação muito particular em relação a todos os outros ensinos e aponta a uma primeira pergunta sobre aquilo que se entende por "compreender". Aqui, divergências profundas aparecem entre o ponto de vista matemático e o ponto de vista cognitivo.

\section{Compreender: poder justificar ou de início reconhecer?}

Do ponto de vista matemático, a compreensão deve responder à exigência epistemológica de prova que é comum a todo conhecimento científico. Sem dúvida, não se trata aqui de demonstrar no senso estrito do termo, mas é necessário ao menos poder explicitar as propriedades utilizadas que "explicam" como se chega à solução de um problema e por que "isto dá certo", ou por que outras soluções "não podem dar certo" mesmo quando elas são aparentemente evidentes (DUVAL, 2011a). Do ponto de vista matemático, a compreensão começa com uma explicação que se baseia na utilização de propriedades matemáticas. A finalidade do ensino é, então, transmitir o conhecimento destas propriedades, dos 
números, das funções, das relações espaciais topológicas, afins, métricas, etc. Nesta perspectiva, o desenvolvimento da compreensão no aprendizado se reduz a um processo de conceituação, isto é, de "construção" de um conhecimento relativo a cada propriedade e a sua utilização matemática ou prática, respeitando as restrições matemáticas sobre suas ordens de aquisição.

De um ponto de vista cognitivo, a compreensão é guiada pelo modo de acesso aos objetos estudados. Fora deste ponto de vista, os matemáticos se encontram em uma situação epistemológica totalmente à parte em relação às outras disciplinas científicas, mesmo se eles dividem a mesma exigência de prova. $\mathrm{O}$ acesso aos objetos matemáticos não é nem sensorial nem instrumental, como em física ou em química, mas ele passa pela produção de representações semióticas que não devem jamais ser confundidas com os objetos que elas representam (DUVAL, 2008). Do ponto de vista cognitivo, compreender em matemática é, antes de tudo, reconhecer os objetos matemáticos representados.

Este reconhecimento atinge rapidamente um duplo obstáculo. Existe, de início, o fato de que muitas destas representações dão lugar a um reconhecimento imediato que, feito, vai de encontro ao reconhecimento daquilo que é matematicamente representado. É o caso, por exemplo, de todas as representações cujo conteúdo é puramente visual, como as figuras em geometria, os grafos, os gráficos, etc. Elas impõem um reconhecimento perspectivo e icônico das formas que impedem de ver aquilo que é matematicamente representado; assim o uso da linguagem natural em matemática é bastante equivocado. Isto já aparece com os termos antagônicos utilizados nos enunciados de problemas para qualificar números fornecidos ou números a ser encontrados e que designam ao mesmo tempo quantidades ou grandezas e operações sobre os números relativos "ganhar/ perder", "aumentar/diminuir", etc. Existe sobretudo o paradoxo cognitivo que sustenta a impossibilidade cognitiva de um duplo acesso aos objetos matemáticos: falta de acesso perceptivo ou instrumental de um lado, e somente um acesso semiótico. O problema crucial da compreensão no aprendizado da matemática leva a este paradoxo. Ele insere os alunos em uma questão que se pode representar pelas duas perguntas formuladas a seguir: como reconhecer que duas representações semióticas diferentes são representações do mesmo objeto, se não se tem um acesso não semiótico àquilo que é representado? Inversamente, como reconhecer que duas representações semióticas diferentes cujos conteúdos são quase equivalentes representam ou não representam dois objetos diferentes, se somente se dispõe destas representações?

A divergência entre estas duas abordagens de critérios de compreensão parece ser tão forte que, se colocada sob um ponto de vista, parece perder o outro. Do ponto de vista matemático, a abordagem cognitiva nos conduz a ignorar os conteúdos matemáticos e a esquecer que não se pode aprender matemática 
sem "fazer" um pouco de matemática. Assim, é evidente que, face aos trabalhos dos alunos, os professores reagem quando estimam que seus alunos "não entenderam". Do ponto de vista cognitivo, "fazer" matemática exige atitudes intelectuais que não estão ligadas a um conteúdo matemático particular e que, além disso, não são nunca solicitadas em outras disciplinas. Isto se deve a que as maneiras de raciocinar, de definir, de ver e de propor problemas não são os mesmos da matemática e fora dela. O que ocorre com mais frequência é esta diferença incompreensível, e nunca explicada, quando os estudantes dizem "eu não entendi" ou "eu não entendi nada".

\section{Os processos cognitivos do reconhecimento dos objetos matemáticos}

Ser capaz de reconhecer o mesmo objeto em duas representações semióticas diferentes implica que, se uma só é dada, é possível espontaneamente convertê-la em outra e mesmo em uma terceira. Esta é a primeira condição para ser capaz de começar a procurar pela solução de problemas. Em matemática, reconhecer um objeto representado e converter a representação dada para outras representações levantam os mesmos processos cognitivos. Isto não é uma questão de memória ou de associação, uma vez que o fato de já ter visto as representações dadas e aquelas que devem ser trabalhadas não ajuda em nada.

Dois pontos são essenciais para analisar o funcionamento cognitivo das representações semióticas. De início o conteúdo de uma representação, quer dizer, o que ela apresenta explicitamente nunca é o objeto em si mesmo se ele parece ter uma semelhança, como no caso das imagens (as representações icônicas de Peirce). Em seguida, e sobretudo, o conteúdo de uma representação semiótica ou não semiótica depende do sistema semiótico, físico ou neurológico, que é especificamente trabalhado para produzir a representação e não somente o objeto representado. Isto ocorre porque os conteúdos das representações de um mesmo objeto mudam completamente conforme o sistema que foi trabalhado para produzir uma representação. Existem muitos conteúdos potenciais diferentes para representar um objeto, e sistemas diferentes permitem a produção de uma representação. Como já foi dito anteriormente, os objetos matemáticos possuem esta particularidade, isto é, seu acesso está restrito a uma única produção de representações semióticas.

Os processos cognitivos de reconhecimento de um mesmo objeto matemático estão baseados em fazer a correspondência entre as unidades de sentido que se podem distinguir dos conteúdos respectivos de duas representações diferentes. O reconhecimento não resulta do conhecimento anterior do objeto ou de uma de suas propriedades. Tomemos um exemplo clássico: uma "situação problema" de divisão dada aos alunos de 7-8 anos para introduzir a noção de 
divisão. Uma professora propõe o seguinte enunciado, acompanhado de um material para ajudar a compreensão do enunciado e para fazer as manipulações. Em seguida, após os alunos efetuarem as manipulações, ela pede para desenhar o que eles representaram com o material (VANHEULE-HAEK, 2001).

Figura 1 - Uma situação contendo um problema de divisão

\section{ENUNCIADO DESCRITIVO}

\section{Uma situação de divisão:}

Transportam-se 30 carros em vagões.

Cada vagão pode transportar 3 carros.

Quantos vagões são necessários para transportar todos os carros?

\section{MATERIAL (manipulação)}

Retângulos para os vagões

Traço para os carros

Fonte: $\mathrm{O}$ autor.

A apresentação deste problema mobiliza três registros, mas a atividade cognitiva que permite tomar consciência da divisão exige uma correspondência das unidades de sentido dos conteúdos de dois tipos de representação: de um lado, a dupla sequência de unidades representadas por retângulos e por traços e, de outro lado, a dupla sequência de números correspondendo respectivamente a contagem dos retângulos e dos traços (representamos por flechas as diferentes correspondências das quais os alunos devem ter consciência).

Figura 2 - As diferentes correspondências entre as unidades de sentido dos conteúdos das representações

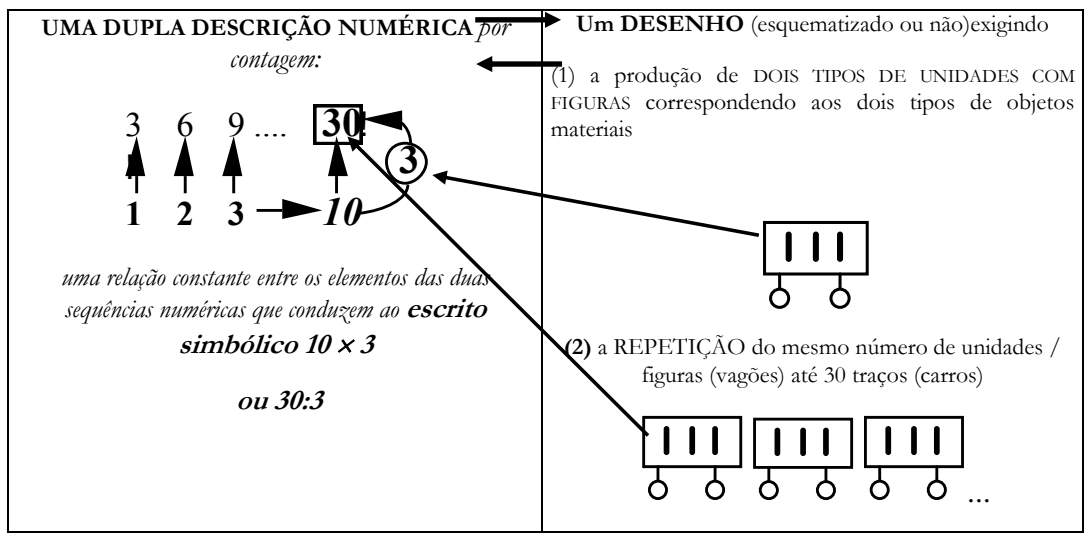

Fonte: Duval (2008, p. 48).

Os desenhos dos alunos e a conta feita sobre o desenho fizeram aparecer dois tipos de dificuldades. De início, para alguns, dificuldades no nível de produção de um desenho que respeite os dados do enunciado. Em seguida, e é o mais importante aqui, a ausência de consciência da dupla descrição numérica do desenho que eles tinham feito para representar o número de vagões em função do número de 
carros. Isto se traduziu pela única escrita de uma sequência de operações de soma, na qual, para obter o número 30: isto é, $3,3 \ldots$, seja $3+3+\ldots$ Em outras palavras, não há nenhuma tomada de consciência da correspondência entre as duas contagens e os dois tipos de unidades figuradas produzidas.

De um ponto de vista cognitivo, a necessidade de uma representação de duas contagens em duas sequências paralelas de números era tão essencial quanto a necessidade de um desenho a partir do material dado e manipulado. Isto se deve à condição para que seja feita a dupla correspondência de unidades de sentidos que é requisitada para começar a tomar consciência das operações de multiplicação e de divisão.

- aquela que é a conversão do desenho em um escrito de números coerentes com o conteúdo do desenho, o qual é composto de dois tipos de unidades figuradas a serem contadas separadamente.

- aquela entre os termos sucessivos das duas sequências de números. Ela permite observar a constância de uma relação quando se passa de um termo de uma sequência ao termo correspondente de outra.

Pode-se então observar os dois impasses da organização da sequência da atividade, que a professora tinha, portanto, de maneira admirável, organizado segundo os critérios didáticos ensinados em formação dos professores. De início, o desenho não serve a nada por ele mesmo se não for coordenado com um outro tipo de representação. Neste caso, esta é uma descrição numérica por contagem. Em seguida, tem-se a dupla descrição numérica que é implícita e rapidamente mobilizada pela produção de desenhos dos dois tipos de unidades figuradas na escrita de única sequência de números. Tudo se passou como se o conteúdo da escrita das operações multiplicativas $(10 \times 3$ e 30:3) tivessem sido identificadas na operação matemática por si mesma. Pode-se ver também que os objetivos de uma sequência de ensino para introduzir a operação de divisão deveriam ter sido combinados de forma múltipla e heterogênea, uma vez que a situação problema de divisão assim o exigia para que a finalidade do aprendizado fosse atingida. Nada surpreendente então que a professora tenha concluído que o desenho era uma fonte adicional de dificuldades ao invés de ser uma ajuda ou meio de construir uma "imagem mental", como ela havia acreditado, e que ela tenha renunciado em seguida a tal recurso para este tipo de aprendizado.

Este exemplo não tem nada de excepcional. Encontramos os mesmos curtos-circuitos cognitivos em quase todas as análises de resolução de problemas que foram escolhidas para introduzir novos conceitos e nas variáveis didáticas selecionadas para organizar as sequências de atividades em sala de aula. 


\section{Compreender do ponto de vista psicológico e pedagógico}

Existem, evidentemente, pontos de vista para determinar critérios de compreensão no aprendizado da matemática. Embora os pontos de vista sejam periféricos em relação aos critérios matemáticos e cognitivos, porque eles não levam em conta a exigência epistemológica comum a todo conhecimento científico e aquela da situação epistemológica específica aos matemáticos, eles são, contudo, importantes para poder avaliar as reais aquisições ao final de um ciclo de ensino ou de contribuição.

Do ponto de vista psicológico, os critérios de compreensão são relativos não tanto aos desempenhos - sucesso ou fracasso - quanto as suas modalidades. Dois critérios são então importantes. O primeiro é o tempo de reação ou de resposta. Assim, não é absolutamente a mesma coisa ter sucesso em tarefas que pedem somente poucas operações ou transformações de representação, em dois minutos, dez minutos ou mais de meia hora. A compreensão implica uma relativa espontaneidade de resposta, porque, sem esta rapidez, não há mais nenhuma disponibilidade de atenção possível quando outras informações ou outras tarefas devem ser consideradas no mesmo tempo. É o que os psicólogos chamaram a "sobrecarga cognitiva". O segundo critério é a possibilidade de transferência, a qual é frequentemente entendida no sentido de uma aplicação a outros contextos que aquele no qual se fez o aprendizado. Mas, de fato, diz respeito à possibilidade de facilitar outros aprendizados que se farão mais rapidamente. Neste sentido, a compreensão implica o desenvolvimento da capacidade de "aprender a aprender". Mais concretamente, isto significa que a compreensão desenvolve uma capacidade de iniciativa e de controle em situações que são inteiramente novas para o sujeito, o que é o caso, por exemplo, para a resolução de problema.

O ponto de vista pedagógico se baseia na vivência dos alunos, quer dizer, no que eles sentem quando são colocados em situação de aprendizado. Cada aluno tem uma personalidade e uma história próprias. Aqui outros fatores intervêm: o interesse pelas tarefas ou pelos tipos de atividades propostas (a "motivação"), a interação com outros alunos em função da situação na sala de aula ("igual aos outros ou melhor") e a "confiança em si" e em suas próprias capacidades. São geralmente os dois primeiros critérios pedagógicos que chamam a atenção e que são levados em conta para a organização do trabalho em sala de aula. Mas é o terceiro que determina um critério de compreensão, porque ele é um efeito imediato deste critério, em que a compreensão é vivida como uma experiência de autonomia intelectual. Este critério junta-se ao critério psicológico do desenvolvimento da capacidade de aprender. 


\section{Questões metodológicas relativas ao estudo dos problemas de compreensão no aprendizado da matemática}

São os trabalhos dos alunos, obtidos no quadro das atividades a eles pedidos, que permitem estudar os problemas de compreensão em matemática. Eles constituem os únicos dados que possibilitam extrair as condições e as variáveis cognitivas que devem ser consideradas no aprendizado da matemática. Enquanto que a interpretação matemática dessas condições e variáveis, com uma finalidade de avaliação, não apresenta nenhuma dificuldade maior, sua utilização no trabalho de pesquisa coloca duas questões de ordem metodológica. Quais situações de produção permitem observar os fenômenos de incompreensão e de compreensão? Como analisar os trabalhos gravados, de maneira a que a interpretação deles traga conhecimentos úteis sobre os fatores de desenvolvimento da compreensão da matemática para todos os alunos, sobre um período de uma década, de 6 a 16 anos?

\section{Quais são os dados para estudar os fenômenos de compreensão e de incompreensão}

As publicações e as teses se referem essencialmente a uma destas três situações de produção: a aplicação de questionários, a resolução de problemas e a observação de uma sequência de atividade em sala.

Os dados assim obtidos parecem ter um valor diferente. As respostas a questionários são facilmente quantificáveis e se prestam então a tratamentos estatísticos, mas elas não dão ou dão poucas indicações sobre as etapas que conduziram cada aluno a produzir suas respostas. É um pouco inversa a situação para a resolução de problemas e para a observação do trabalho em sala. O que diferencia estas duas situações é que uma corresponde ao trabalho matemático enquanto que a outra é aquela das condições reais de aprendizado relativas ao professor. Contudo estas diferenças são muito relativas, porque a confiança e o valor informativo dos dados recolhidos não mantêm o caráter "live" ou não das observações feitas, mas a escala de tempo na qual elas são feitas e ao objeto de observação que se chama muito genericamente “o aluno", quer dizer todos e nenhum.

As observações podem ser feitas em três níveis de tempo diferentes. Pode ser a duração de uma hora de aula ou de uma sequência de atividade; pode ser o ano escolar com seu programa, e, neste caso, as observações são feitas não ao fim de uma sequência de aprendizado, mas alguns meses mais tarde. Enfim, pode ser o currículo, que é quando se olha aquilo que os alunos compreenderam ou adquiriram relativamente aos conteúdos ensinados vários anos antes. É evidentemente a esta escala de tempo que os professores de um ciclo se colocam 
quando eles reagem sobre o "nível" de seus alunos, quer dizer, sobre aquilo que eles adquiriram ou não nos ciclos anteriores do aprendizado. Um exemplo muito simples relativo às respostas de um problema de soma dado a futuros professores do início do Ensino Fundamental e que estavam no quarto ano da universidade: um fracasso massivo e persistente. Os únicos futuros professores para quem era trivial este problema vinham de carreiras científicas (DUVAL, 2011b, p. 126).

Existem três maneiras totalmente diferentes de escolher "o aluno" a quem se vai observar e gravar os seus trabalhos. Pode-se observar o que fazem alunos analisados individualmente, porque ninguém pode realmente compreender em seu lugar. Os conhecimentos matemáticos nunca são diretamente comunicáveis porque as soluções somente têm sentido e se tornam passíveis de utilização a partir da etapa que permite encontrá-las. Somente se compreende aquilo que se pode fazer e encontrar por si mesmo. Pode-se também não mais olhar os alunos, mas a sala de aula, quer dizer um ou vários grupos de alunos trabalhando em "interação" conforme as instruções e o tempo dado pelo professor. Então, muito frequentemente não vale mais a pena distinguir aquilo que cada um dos alunos faz ou não faz, mas se contenta em ver se globalmente a sequência "funcionou", quer dizer se o professor conseguiu fazer com que os alunos participassem nas diferentes fases de engineering previstas. Enfim, podemos nos colocar na escala de um sistema educativo. Interessa então aquilo que a população inteira de um país teria, ou não teria adquirido, em relação aos objetivos de ensino considerados como sendo matematicamente e culturalmente indispensáveis. As pesquisas de avaliação nacionais e internacionais visam a este tipo de informação.

Qualquer que seja a situação de produção obtida, a confiança e o valor informativo dos dados colhidos, se poderá avançar com base nas conclusões dependendo, de início, daquilo que se poderia chamar de parâmetros dos dados colhidos.

Existe enfim a exigência científica comum relativa à interpretação dos dados colhidos. Para interpretar dados colhidos em condições determinadas, é necessário poder compará-los a outros dados obtidos em condições que diferem por uma variação controlável. Em outras palavras, os dados não se interpretam diretamente, mas indiretamente. Interpretam-se as diferenças entre todos os dados obtidos a partir da variaģão de uma das condiçoes nas quais eles foram obtidos. Encontra-se aqui a primeira exigência científica na organização de todo dispositivo de observação ou de experimentação. Para as pesquisas em didática, isso significa que a verdadeira questão metodológica não é aquela da escolha da situação de produção, questionário, resolução de problema, atividade em sala de aula, mas aquela da organização de um dispositivo que vai responder a esta exigência de comparação. 


\section{Como analisar os trabalhos dos alunos no aprendizado da matemática?}

A análise dos trabalhos dos alunos deve ser feita em dois níveis com, evidentemente, critérios totalmente precisos para cada um deles porque a questão que comanda a análise não é a mesma.

O primeiro nível é aquele da avaliação matemática dos resultados, dos processos, das propriedades ou dos argumentos utilizados. Eles são matematicamente "verdadeiro" ou "falso" e, como para tudo aquilo que se relaciona com a execução de uma tarefa, esta avaliação é traduzida em "acertos" e "erros". Nos trabalhos de pesquisa esta duplicidade constitui a base de toda a codificação de dados.

O segundo nível é aquele da análise da compreensão em que os sucessos se manifestam e aquele das fontes de incompreensão. É nesse nível que se encontra a questão da escolha dos critérios de compreensão, quer dizer, do ponto de vista adotado para analisar os sucessos: o sucesso matemático em uma tarefa implica a compreensão da maioria dos alunos? A análise da incompreensão que os erros manifestam é uma análise mais complexa.

\section{Qual é o critério de compreensão para analisar os "sucessos" em uma perspectiva de aprendizado?}

Como foi visto acima, pode-se se basear no critério matemático. Neste caso, olha-se se as respostas ou as soluções "verdadeiras" são explicadas fazendo uso das propriedades pertinentes ou se elas permitem induzir o conhecimento. $\mathrm{O}$ critério é também aquele que os esquemas didáticos da organização de sequências de ensino privilegiam. Eles visam à "construção dos conceitos" pelos alunos e colocam em evidência a justificativa de toda resposta avançada.

Mas pode-se também tomar o critério cognitivo. Neste caso, olha-se se os alunos reconhecem um mesmo objeto matemático através das representações diferentes que podem ser dadas e se eles podem reconhecer aquilo que é matematicamente diferente quando se modifica alguma coisa no conteúdo de uma representação. O artigo Gráficos e Equações, publicado em 1988 (e em Português, no ano de 2011), é a primeira análise que foi feita em função deste critério cognitivo de compreensão. Ele se baseava no reconhecimento das funções afins pelos alunos de 15-16 anos, após um ensino de vários meses sobre estas funções.

O tipo de tarefa que permite estudar o reconhecimento dos objetos representados é uma tarefa de conversão de representação. Evidentemente, este tipo de tarefa parece pouco matemática, mas a conversão das representações é implicitamente e necessariamente requisitada em toda atividade de resolução de um problema, e toda 
explicação matemática em sala de aula o faz. A situação de produção escolhida foi aquela de um questionário. Mas, ao contrário dos questionários de avaliação, ele foi organizado conforme a exigência científica geral para a interpretabilidade dos dados (seção 2.1). As variações de um item a outro baseavam-se na modificação de um dos valores visuais matematicamente pertinentes à alocação de uma reta no plano cartesiano. Variações análogas eram feitas para diferentes regiões do plano cartesiano delimitadas pelos eixos e pelas bissetrizes dos ângulos dos eixos. Toda atividade de cálculo deveria ser excluída para estudar o reconhecimento dos objetos representados, pois o trabalho requerido era a escolha entre diferentes escritas algébricas. Este tipo de trabalho apresenta também a vantagem de controlar o tempo necessário para que um aluno "tenha sucesso", porque os sucessos não têm o mesmo significado se eles são obtidos quase que espontaneamente (o tempo de leitura dos diferentes escritos algébricos propostos) ou, se ao contrário, foram necessários vários minutos por item. Assim, os professores puderam definir tempos diferentes de prova, o que dava baixas importantes nas porcentagens de sucesso.

Pode-se então depreender o método necessário para analisar os resultados em termos de compreensão ou de aquisição dentro de uma perspectiva de aprendizado. Assim, levantam-se três questões:

-1) É necessário considerar os itens tomados isoladamente com suas porcentagens, aluno médio ou fraco, ou somente sequências de itens, o sucesso sendo então em relação a todos os itens da sequência?

-2) Em relação a que se devem regrupar os itens em uma sequência que, sozinha, será considerada como sucesso?

- 3) São os sucessos ou as diferenças de sucessos a questões que se baseiam sobre o mesmo objeto que são significativos?

Para a primeira pergunta, mantém-se quase sempre a primeira alternativa que consiste em considerar implicitamente que o sucesso matemático na resposta a uma pergunta é um indicador de compreensão ou já implica uma compreensão pelo aluno. De um ponto de vista cognitivo, os itens isolados não são realmente passíveis de interpretação, sendo necessária uma sequência de itens. Assinalemos também que os resultados quantitativos não são os mesmos se considerarmos os itens separadamente ou se os sucessos forem considerados a partir de seus reagrupamentos em sequências. Porque no segundo caso, antes de efetuar os tratamentos estatísticos, é necessário efetuar uma segunda codificação para os reagrupamentos de itens já codificados em acertos, erros ou ausência de resposta. Isto conduz frequentemente a conclusões totalmente diferentes.

A segunda pergunta é crucial. Os agrupamentos dos itens em uma única sequência dependem das variações que determinaram a construção do 
questionário em itens. No questionário de 1988 sobre as funções afins, três variáveis figuradas foram levadas em conta para a alocação de uma reta sobre o plano cartesiano: o sentido de inclinação, o ângulo formado com os eixos e a interseção com o eixo das ordenadas. Para cada uma das variáveis figuradas, dois valores foram retidos. Pode-se então considerar como uma sequência os dois valores opostos para cada uma das três variações figuradas, por exemplo, o reconhecimento de $y=x$ E de $y=-x$ ou $y=2 x$ E de $y=\frac{1}{2} x$. Porque reconhecer o que o grafo representa é ser capaz de distingui-lo de um outro grafo que apresente ao menos um valor figurado oposto.

Portanto, sobre as representações afins, o questionário de 1988 apresenta uma limitação. A tarefa de conversão é proposta somente em um sentido: gráficos versus equações. A conversão inversa não foi solicitada por uma razão simples. É ela que é privilegiada para introduzir as representações gráficas como codificação de pontos por duplas de números: é suficiente tomar duas duplas de números para colocar uma reta sobre o gráfico. Ela promove uma leitura local dos grafos e gráficos sem desenvolver esta apreensão global qualitativa e não icônica que leva um conteúdo intuitivo aos múltiplos escritos algébricos de relações e que fornece um instrumento cognitivo de controle. Para as representações de superfícies quadráticas, para as representações de outras funções ou para representações de desigualdades, torna-se essencial que as tarefas de reconhecimento comportem os dois sentidos de conversão. Assim sendo, metodologicamente isso exige que os itens, que se baseiam sobre a conversão direta e aqueles baseando-se sobre a conversão inversa, sejam reagrupados ou contabilizados como um único "sucesso" e não como respostas a questões diferentes e, portanto, de sucessos diferentes. De um ponto de vista cognitivo, o reconhecimento implica a espontaneidade das conversões, qualquer que seja o sentido nos quais elas devam ser efetuadas. Pode-se então ver que, com muita frequência, o sucesso matemático a itens não implica a compreensão do ponto de vista cognitivo.

A terceira pergunta se baseia na possibilidade de uma interpretação direta do sucesso ou de uma taxa de sucesso a uma pergunta. É importante lembrar que toda interpretação direta de sucessos se faz em relação a um objetivo de aquisição. Encontra-se então em uma perspectiva de avaliação com incerteza, por exemplo, de saber a partir de qual taxa de sucesso se falará em aquisição. Numa perspectiva de pesquisa, a interpretação dos sucessos não se faz em relação a um objetivo de aquisição, mas em relação às variações introduzidas na organização das tarefas dadas. Ela somente pode se basear nas diferenças de vitórias. Assim, pode-se observar regularmente, para as funções afins, quedas espetaculares de sucessos entre as questões relacionadas com o sinal do coeficiente e aquelas relacionadas com o valor do coeficiente. Esta observação constituiu um resultado 
importante relativo às condições exigidas para compreender e ver as representações gráficas na sua ligação com o registro algébrico. Ela permitiu identificar as diferentes variáveis figuradas matematicamente importantes que os alunos devem ser capazes de distinguir na alocação de uma reta no plano cartesiano, para poder reconhecer o grafo, não importando qual função afim em particular.

\section{A análise dos erros: fonte de informações ou impasse?}

Os erros constituem frequentemente uma parte importante dos dados colhidos. A análise deles provoca dois problemas. O primeiro é aquele da pesquisa da origem dos erros. A dificuldade vem do fato de que não se pode mais utilizar aqui os critérios de compreensão como na análise dos sucessos. Procura-se explicar os erros por "equívocos", quer dizer, "por uma lógica própria do pensamento da criança" que somente manteria certos aspectos de um conceito ou de um processo matemático. Mas procura-se também explicá-los pela complexidade epistemológica das noções matemáticas ensinadas, as quais condensam às vezes um longo desenvolvimento histórico. O segundo problema é aquele de sua utilização para descrever os processos ou os percursos pelos quais os alunos descobririam as noções matemáticas. Pode-se também ordenar os diferentes tipos de erros em função de suas distâncias a um sucesso matemático esperado como se isso permitisse modelar o desenvolvimento da compreensão na aquisição dos conhecimentos. Mas isto somente pode valer para o subgrupo de alunos que, ao final de um ou vários anos de ensino, consegue compreender e utilizar os conceitos e os processos matemáticos.

Existem, de fato, dois tipos de erros radicalmente diferentes: os erros transitórios e os erros recorrentes, jamais vencidos. Os primeiros são diretamente ligados a uma noção ou a um processo matemático particular, por exemplo, a divisão, a simetria dos eixos, a resolução da equação, o teorema de Thales, etc. Eles aparecem somente quando este conteúdo matemático é diretamente utilizado e chamam a atenção dos professores durante o período de tempo dedicado a aquisição do conhecimento. Os segundos são independentes de todo conteúdo particular, ou mais exatamente transversais a todos os conteúdos, porque eles são relativos à maneira de ver, de definir, de raciocinar, de trabalhar matemática. Eles manifestam dificuldades de compreensão que se encontram em todos os níveis do currículo e que muitos não superam.

Esses dois tipos de erros são raramente distinguidos porque, na origem da formação de professores ou na esperança de ver ao vivo a maneira como os alunos pensam, a maioria das pesquisas didáticas se limitam às observações feitas na escala de tempo de uma hora ou de uma sequência de atividade de 2 ou 3 semanas. Neste caso, todos os erros são assimilados como transitórios, que 
dizer, como dificuldades ligadas à compreensão de um conteúdo matemático particular a adquirir. Faz-se como se as maneiras de ver, de pensar, de raciocinar e mesmo de ter acesso aos objetos fossem as mesmas em todos os outros domínios do conhecimento. Mas a irredutibilidade dos erros recorrentes às dificuldades próprias à complexidade epistemológica de cada conceito aparece quando se fazem observações em períodos mais longos e em um nível de abrangência de um ou mesmo dois ciclos de ensino.

Ao contrário dos erros transitórios, os erros recorrentes devem, de início, ser analisados em relação a este funcionamento cognitivo particular do pensamento que toda atividade matemática requer e mobiliza.

\section{Pontos de vista e teorias nas pesquisas sobre o ensino da matemática}

O ensino da matemática implica que se leve em conta outros pontos de vista e não somente o único ponto de vista matemático sobre os conteúdos a ensinar. Isto se impõe especialmente pelo fato de que o ensino se dirige a uma maioria esmagadora de alunos que não pretendem fazer estudos superiores em matemática ou em física. Todos estes outros pontos de vista baseiam-se sobre tudo o que constitui o objeto das pesquisas didáticas: a aquisição de conhecimentos matemáticos que se destinam à formação geral ou a formação especializada. Esta última observação é importante porque ela marca a separação entre os diferentes pontos de vista sobre os processos de aquisição de conhecimentos matemáticos.

Assim, o ponto de vista da compreensão e dos aprendizados pelos alunos é independente de todo objetivo de formação, como mostram os bloqueios e as dificuldades recorrentes que se encontram em todos os níveis de ensino e em todos os sistemas educativos. O ponto de vista dos objetivos do ensino da matemática, seja no quadro da formação geral ou no das formações especializadas, é aquele da escolha de conhecimentos a ensinar e de sua organização em um programa, em um currículo ou em uma linha de formação. Este ponto de vista é aquele dos responsáveis institucionais, dos especialistas, etc. O ponto de vista da organização e da gestão das atividades em sala pelos professores é, por outro lado, determinado pelos conteúdos matemáticos assim definidos, os quais eles devem fazer os alunos adquirirem em um ano escolar.

Esta diversidade de pontos de vista sobre a aquisição de conhecimentos matemáticos levanta várias questões sobre a escolha e a adequação das "teorias" utilizadas nas pesquisas didáticas. Estas questões são importantes porque as respostas que são dadas, implicitamente ou explicitamente, envolvem a maneira de conduzir uma pesquisa em didática e a contribuição que se pode esperar dela. 


\section{Existe um ponto de vista que seja mais central que os outros para as pesquisas sobre a aquisição dos conhecimentos matemáticos?}

Os pedidos institucionais relativos à formação dos professores levaram rapidamente ao privilégio do ponto de vista do professor e ao desenvolvimento de esquemas globais de organização das atividades que sejam aplicáveis em sala. Estes esquemas globais devem (1) responder à exigência institucional da aquisição dos conteúdos matemáticos que são definidos no quadro do programa; (2) dar os critérios para escolha das atividades em função dos processos cognitivos de aquisição de conhecimentos; e (3) colocar os alunos em uma situação que os levem a investir nas atividades propostas.

A questão que esta abordagem levanta reside de início no item 2: quais são os processos cognitivos que permitem compreender e adquirir conhecimentos em matemática? Esta questão é crucial, porque ela reformula a questão dos processos de aquisição dos conhecimentos: são eles os mesmos em matemática que aqueles que são espontaneamente utilizados em outras áreas do conhecimento ou, ao contrário, o pensamento e o trabalho em matemática exigem um modo de funcionamento cognitivo diferente e, às vezes, contrário ao funcionamento cognitivo espontâneo?

Quase todas as pesquisas didáticas trazem um impasse sobre esta questão, porque elas recorrem a teorias do funcionamento cognitivo do pensamento supostamente válidas para todas as áreas de conhecimento. Um consenso se estabeleceu rapidamente para retomar, desde os anos 1970 e 1980, a explicação de Piaget da formação dos conceitos no universo da criança, embora esta explicação seja relativa tanto a noções físicas quanto a noções matemáticas muito gerais e tenha sido elaborada a partir de observações e de provas que não tinham nenhuma tarefa matemática. A teoria de Piaget apresentava a vantagem de parecer responder à exigência institucional (1), e ela permitia retomar, naquilo que foi chamado "construção de conhecimentos" pelo aluno, as duas ideias principais desta teoria olbando somente como critério de compreensão o único critério matemático (Seção 1.1). De uma parte, a adaptação ao meio como mecanismo da formação dos conceitos justificaria a importância da resolução de problemas para aprender matemática; de outra parte, a distinção de níveis de desenvolvimento nestas aquisições. O primeiro como aquele das ações e das manipulações concretas bem antes do recurso à linguagem a toda representação semiótica, o que foi representado em esquema de aprendizagem para a introdução dos conceitos. Mas para o ponto (3) foi necessário usar outras teorias para explicar o papel importante das interações verbais das atividades dadas em sala de aula. 
O estudo dos problemas de compreensão e de aprendizagem em matemática exige, ao contrário, que se coloque no ponto de vista dos alunos e se parta de seus trabalhos individuais e que as observações sejam feitas em uma escala de tempo que não seja somente aquela de uma sequência de atividade centrada na introdução de uma noção ou de um processo (Seção 2.1). Não é mais possível se ter impasse sobre a situação epistemológica da parte da matemática em relação às outras ciências. A maioria dos erros e dos bloqueios recorrentes vêm do fato de que os alunos, ao ficarem no funcionamento cognitivo espontaneamente utilizado em outras áreas de conhecimento, mas que frequentemente é contrário àquele exigido quando são o único acesso aos objetos estudados, passam por representações semióticas (Seção 1.2). Assim, sem uma tomada de consciência das variáveis figuradas matematicamente pertinentes, os alunos só podem se ater a uma interpretação icônica e sincrética dos grafos e dos gráficos, sem ligação com o registro algébrico.

Os registros de representação semiótica são uma descrição do modo de funcionamento cognitivo subjacente a toda atividade matemática, qualquer que seja a área, atividades numéricas, geometria, álgebra, análise, etc. O interesse dos registros de representação semiótica é determinar as variáveis didáticas que tocam diretamente os fenômenos de compreensão e de incompreensão no aprendizado da matemática (DUVAL, 2011b).

\section{Qual é a relação entre o ponto de vista matemático e o ponto de vista semicognitivo para a organização de situações de aprendizado?}

Ao contrário dos modelos psicológicos ou construtivistas, existe uma incompatibilidade na abordagem dos processos de aquisição de conhecimentos matemáticos entre o ponto de vista matemático e o ponto de vista semicognitivo. Do ponto de vista matemático, a prioridade deve ser dada aos conteúdos, quer dizer às propriedades dos objetos matemáticos estudados, assim como a sua utilização segundo os critérios matemáticos de compreensão. Do ponto de vista semicognitivo, a atividade matemática consiste em dois tipos de transformação de representações semióticas. A tomada de consciência das diferentes representações possíveis para um mesmo objeto e a ligação de seus conteúdos respectivos são a primeira condição para entrar na maneira de pensar própria dos matemáticos e para desenvolvê-la.

Não se trata, certamente, de contestar o fato de que é somente a partir dos conteúdos matemáticos que os alunos podem compreender e aprender em matemática. A fragilidade ou a impertinência das teorias psicológicas e cognitivas "importadas" vêm do fato de que elas são elaboradas a partir de observações ou de experiências feitas com tarefas não matemáticas. Mas também não se trata 
de subordinar o ponto de vista cognitivo ao ponto de vista matemático. Como estes dois pontos de vista podem ser igualmente considerados na organização de situações de aprendizado?

É necessário retomar aquilo que são os "conteúdos matemáticos" os quais os professores têm por encargo fazer os alunos aprender. Eles não derivam diretamente do ponto de vista matemático, mas do ponto de vista institucional sobre a organização do ensino das ciências matemáticas. De fato, a determinação dos conteúdos a ensinar resulta de dois tipos de reflexão e de decisão radicalmente diferentes. O primeiro baseia-se na determinação dos objetivos que se atribuem ao professor de matemática na formação dos alunos. Eles não podem ser os mesmos no ensino geral comum e nas diferentes carreiras especializadas. Mas eles implicam a escolha de um complexo de conhecimentos relativo a um objeto matemático; por exemplo, as funções afins ou as equações (de primeiro ou de segundo grau) sendo dado que a aquisição deste complexo de conhecimentos implica sua utilização para resolver problemas. O segundo tipo, o mais importante para a pesquisa, baseia-se na decomposição deste complexo de conhecimentos em elementos de base que serão objeto de aprendizados sucessivos, sobre o período de um ano ou de um ciclo, e que determinarão então vários objetivos secundários de ensino. Logo, não existe uma, mas duas maneiras de efetuar esta decomposição de um complexo de conhecimento em elementos de base.

A primeira é evidentemente matemática. Explicitam-se os conhecimentos matematicamente pré-requisitados para compreender o complexo de conhecimentos relativos a um objeto e de apropriá-lo. Em seguida, reitera-se esta análise sobre estes primeiros pré-requisitos até que se obtenha uma sequência de elementos de base que vão constituir os conteúdos matemáticos que os alunos deverão adquirir em um ou vários anos. Cada pré-requisito assim isolado pode se tornar um objetivo secundário de ensino. Esta decomposição top-down determina a progressão do ensino obtido nos programas. Estes programas seguem a ordem inversa da decomposição: voltam-se os elementos de base ao complexo de conhecimento, cuja aquisição é objetivo ao fim de um ciclo. Também, quando se fala de "construção de conhecimentos" pelo aluno, é na realidade a Reconstrução bottom-up daquilo que foi matematicamente decomposto em termos de pré-requisitos que se pede aos alunos para fazer. $\mathrm{O}$ ensino da álgebra para alunos de 11 a 15 anos é uma ilustração perfeita (DUVAL, 2011a).

A segunda é cognitiva. Explicitam-se os gestos intelectuais requisitados para a compreensão e aquisição do complexo de conhecimento tido como objetivo de formação. Os gestos intelectuais são as operações semicognitivas das quais os alunos devem ter tomado consciência para poder trabalhar, de maneira autônoma, em um campo de atividades e de problemas. Para a álgebra, por exemplo, dizem respeito à redesignição indireta dos objetos, os jogos de substituição e 
combinação de duas designações diferentes de um mesmo objeto, a observação das ocorrências de sinais em uma expressão, e não mais sobre os próprios sinais para poder efetuar os cálculos, etc. Para a geometria, eles se relacionam, por exemplo, com a desconstrução dimensional das formas que muda completamente o reconhecimento das unidades em função das propriedades enunciadas ou o movimento para resolver um problema, etc. Em síntese, levantamos um funcionamento cognitivo que está em ruptura completa com aquele mobilizado fora da matemática. Os registros de representação semiótica são o quadro de análise para liberar estas operações semicognitivas que devem se transformar em gestos intelectuais familiares para os alunos.

Vê-se então aquilo que restringe o âmbito e os progressos das pesquisas sobre o ensino da matemática, fora certamente da inovação dos instrumentos didáticos que são os programas computacionais para a geometria ou para a álgebra. Esperam-se modelos cognitivos, psicológicos ou outros modelos que expliquem as dificuldades de compreensão encontradas no quadro de decomposição matemática prévia de um conhecimento seguido de conteúdos. Além disso, a maior parte das pesquisas focam sobre um conteúdo particular, considerado como objetivo da aquisição na escala de uma sequência didática de algumas semanas. $\mathrm{Na}$ realidade, a análise cognitiva da atividade matemática em gestos intelectuais não pode ser subordinada a uma decomposição dos conhecimentos matemáticos em termos de pré-requisitos, porque eles são transversais a todos os conteúdos matemáticos. Assim, não haverá progresso decisivo na introdução da álgebra até que as pesquisas tomem, como quadro organizador dos aprendizados, a única progressão bottom-up fundamentada sobre uma decomposição dos conteúdos matemáticos em termos de pré-requisitos. Isso também ocorre de forma semelhante no ensino da geometria no Ensino Fundamental ou Médio.

$A$ atividade matemática comporta duas faces. Existe aquela propriamente matemática centrada nos objetos, nas suas propriedades, nos algoritmos, nas provas, e que leva a uma decomposição dos conteúdos matemáticos a ensinar. Existe aquela cognitiva das maneiras de ver, de raciocinar, de definir, de saltar de uma representação a outra com estes objetos matemáticos que são unicamente acessíveis pelas informações semióticas que se produzem. Esta face é a face oculta da atividade matemática. Ela é o inverso da precedente. Ela não se decompõe em conteúdos mas em atitudes intelectuais. É a aquisição destas atitudes, e somente ela, que dá aos alunos a capacidade de compreender e de saber utilizar conhecimentos matemáticos para resolver problemas na realidade.

Infelizmente, a atividade cognitiva específica na compreensão em matemática não é jamais levada em conta nos objetivos institucionais de formação e nas atividades em sala de aula. A organização do ensino e das situações de aprendizado se mantém com um único eixo de decomposição dos conhecimentos a adquirir, aquele em termos 
de pré-requisitos matemáticos. A utilização da noção geral de "competência” para avaliar aquilo que é adquirido pelos alunos e para descrever as aquisições em termos de um aprendizado é o sintoma mais frequente. $O$ interesse desta noção é que ela é utilizada em todas as áreas de formação e também para determinar qualificações na vida profissional. Ela designa um conhecimento para realizar tarefas bem precisas. Sua fragilidade vem em razão de que os critérios para determinar uma competência dependem do tipo de atividade própria na área onde se vai utilizá-la. Em matemática, o critério para definir competências mantém a decomposição dos conteúdos em termos de conteúdos matematicamente pré-requisitados. Isto conduz a produção e multiplicação das listas de competências a adquirir, porque mesmo o que se considera como um elemento de base na definição de um programa pode sempre ser decomposto em conteúdos secundários matematicamente pré-requisitados.

\section{Quais consequências esta diversidade de pontos de vista traz para a formação dos professores?}

Há mais de trinta anos, a formação dos professores se impôs como a preocupação maior de todas as políticas de educação, particularmente em matemática. Paralelamente, existe a demanda de futuros professores, ou dos professores, sobre "o que fazer" em sala de aula para que seus alunos compreendam os diferentes conteúdos que eles devem ensinar.

É neste contexto que a organização das atividades e a da sua gestão pelo professor se transformaram no objeto principal das pesquisas em didática da matemática. O objetivo das pesquisas é então a elaboração de sequências de atividades, de "engenharias didáticas" que se possam fazer em sala. Trata-se de organizar, no quadro de uma resolução de problema, uma microprogressão no tipo de atividade que se propõe aos alunos. Supõe-se que esta microprogressão no tipo de atividade deve conduzir à construção de um novo conceito, à descoberta de um novo processo de funcionamento. Todo o trabalho de observação vai se concentrar sobre o curso desta microprogressão em uma ou várias salas de aula. Como os alunos participam nas diferentes funções propostas? Como o professor toma conhecimento do que fazem ou do que dizem os alunos? Os dados recolhidos serão as interações orais com o professor e com os outros alunos. É este tipo de dado que é utilizado para validar, na escala específica de algumas sessões e sobre um conteúdo matemático particular, uma sequência de atividade. Mas isto evidentemente aumenta o problema de saber como analisar e interpretar este tipo de dado qualitativo (DUVAL, 2010). 
Ao subordinar a formação dos professores a este tipo de pesquisa, somos conduzidos não somente a privilegiar UM ponto de vista como sendo o ponto de vista principal, mas, da mesma forma, somente a levá-lo em conta como o único eixo de decomposição matemática dos conhecimentos adquiridos. Tudo que é relativo ao que nós chamamos de "face oculta" da atividade matemática e ao aprendizado dos gestos intelectuais se encontram ipso facto retirados, mesmo quando se apresenta a teoria semicognitiva entre todas as teorias didáticas que os professores podem escolher para seus trabalhos de pesquisa. Isto provoca uma verdadeira questão na formação dos professores, porque, na realidade das aulas, os professores se encontram face a uma situação complexa, que resulta na tripla razão para atrasos:

- a inadequação frequente entre a sequência planejada e aquela que os alunos fazem de fato;

- a grande diversidade entre os alunos de uma mesma sala de aula;

- a distância cognitiva e epistemológica entre a matemática e as outras áreas do conhecimento.

Os professores devem então ser capazes, como médicos em consulta, de fazerem dois tipos de diagnóstico a partir do que os alunos propõem e daquilo que eles fazem ou não fazem.

- aproveitar a boa sugestão (do ponto de vista matemático) de um aluno e dividi-la com a classe, mas

- 1) identificar as raz̃oes profundas das incompreensões recorrentes e dos bloqueios, e não somente erros locais no trabalho dado,

- 2) e encontrar as funções ou os exercícios que vão permitir ter acesso aos mecanismos intelectuais necessários para poder resolver problemas não importa qual etapa matemática.

O segundo tipo de diagnóstico é tão fundamental quanto o primeiro e, sobretudo, ele é frequentemente solicitado durante os primeiros anos de ensino, tanto do Fundamental como no Ensino Médio.

Como os professores podem se preparar para isto se toda a formação deles como futuros professores se mantém em uma só face da atividade matemática? Como podem eles reagir de maneira adaptada se eles mesmos não tomaram consciência destas atitudes intelectuais que são o pensamento matemático na prática? 


\section{Conclusão}

Quatro pontos essenciais caracterizam o ensino da matemática:

1) Ensinar exige que nos coloquemos em outro ponto de vista que aquele das exigências matemáticas que determinam a comunicação científica de um resultado ou as discussões entre matemáticos face a um problema para resolver.

2) Os conteúdos matemáticos ensinados sempre resultam da decomposição de um complexo de conhecimento que foi absorvido como objetivo global de aquisição por um grupo de alunos ao fim de um ciclo de estudos. Esta decomposição se dá sempre em termos de conhecimentos matemáticos previamente exigidos. Tal reiteração pode conduzir a isolar conteúdos que se tornam objetivos secundários distintos e sucessivos de aquisição, na escala de tempo de um ano ou de algumas semanas.

3) $\mathrm{O}$ ensino de matemática esbarra em problemas específicos de compreensão que não se encontram em outras disciplinas ensinadas. Estes problemas se baseiam no fato de que o modo de acesso aos objetos matemáticos é radicalmente diferente do modo de acesso aos outros objetos de conhecimento. Isto corresponde àquilo que nós chamamos "a situação epistemológica à parte da matemática". Ela conduz ao paradoxo cognitivo do conhecimento matemático.

4) Estes problemas específicos de compreensão tornaram-se ainda mais importantes, tanto que o ensino da matemática se encontra em uma situação histórica sem precedente desde os anos 1960-1970. Não somente todos os alunos devem estudar matemática até 16 anos, e além, mas as expectativas de formação em matéria de aquisições de base se tornaram mais exigentes e mais variadas em razão das necessidades do desenvolvimento das "altas tecnologias" em todas as áreas de atividade profissional. É por isto que, para a aquisição de conhecimentos matemáticos, toda comparação com situações anteriores parece fictícia.

As pesquisas sobre o ensino da matemática baseiam-se nos problemas que se colocam quando se desloca a um outro ponto de vista que o ponto de vista matemático (1). A escolha das teorias e dos métodos não vai ser a mesma segundo o ponto de vista ao qual se coloca. Neste artigo, nós consideramos essencialmente o ponto de vista cognitivo, aquele sobre o processo e o funcionamento do pensamento. Ele se refere diretamente aos problemas de compreensão (4).

É aí talvez que a escolha de uma teoria é mais delicada e mais decisiva, porque em se atendo ao ponto de vista do professor, a organização de 
sequências de atividades em sala de aula requer, implicitamente ou explicitamente, uma teoria cognitiva, do tipo pragmática, empírica, construtivista ou outra. Esta escolha leva à resposta das três questões seguintes:

5) Podem-se importar teorias cognitivas gerais, estimadas válidas para todas as formas de aquisição de conhecimentos, mas que não levam em conta absolutamente a situação epistemológica a parte da matemática (3), ou é necessário elaborar um modelo de funcionamento cognitivo do pensamento a partir do modo exclusivamente semiótico de acesso aos objetos matemáticos e de uma atividade exclusivamente fundamentada sobre as únicas transformações de representações semióticas?

6) A consideração do ponto de vista cognitivo é compatível com a decomposição dos conhecimentos fixados como objetivo global de aquisição em conteúdos distintos e sucessivos de aprendizagem (2), ou ela exige uma outra decomposição em termos intelectuais matemáticos?

7) $\mathrm{Na}$ análise dos trabalhos dos alunos, os critérios cognitivos de compreensão se reduzem aos critérios matemáticos de sucesso ou, ao contrário, é necessário admitir que o sucesso matemático possa não implicar uma real aquisição de conhecimento?

Quase todas as pesquisas sobre o ensino da matemática têm até agora escolhido a primeira alternativa a estas três questões: utilização explícita ou implícita de teorias cognitivas gerais, análise da compreensão inteiramente focada sobre cada um dos conteúdos, resultantes da decomposição de um complexo de conhecimento, e redução dos critérios cognitivos de compreensão aos sucessos matemáticos locais. A segunda alternativa a estas três questões volta a levar em conta as duas faces da atividade matemática: não é a face exposta, aquela que se decompõe em conteúdos, mas sim a face oculta da maneira de olhar, de raciocinar, de explorar na troca de representações, que é própria aos matemáticos e que deles dependem a compreensão matemática e a capacidade para utilizar os conhecimentos matemáticos. Mas tudo isto nos leva novamente ao ponto de vista institucional. Qual papel se dá ao aprendizado da matemática na formação e no desenvolvimento intelectual dos indivíduos?

\section{Referências}

DUVAL, R. Gráficos e equações: a articulação de dois registros. Revemat, Florianópolis, v. 6, n. 2, p. 96-112, 2011.

. Graphiques et equations: l'articulation de deux registres. Annales de Didactique et de Sciences Cognitives, n. 1, p. 235-255, 1988. 
. Eight problems for a Semiotic Approach in Mathematics Education. In: RADFORD, L.; SCHUBRING, G.; SEEGER, F. (Eds.). Semiotics in Mathematics Education: epistemology, history, classroom and culture. Rotterdam: Sense Publishers, 2008. p. 39-61.

Comment analyser les activités données en classe et les productions des élèves? Cursillo, PUC Valparaiso, 2010.

Dois olhares opostos sobre os pontos críticos do ensino de álgebra no ensino fundamental (11-15 anos). In: SEMINÁRIO INTERNACIONAL DE EDUCAÇÃO MATEMÁTICA - SIEMAT, 3., 2011, São Paulo. Anais... São Paulo: Universidade Bandeirante de São Paulo - UNIBAN, 2011a.

Ver e ensinar a matemática de outra forma: entrar no modo matemático de pensar: os registros de representações semióticas. Organização de Tânia M. M. Campos. Tradução de Marlene Alves Dias. São Paulo: PROEM, 2011b. v. 1.

VANHEULE-HAECKE, N. Traiter du partage au cycle 2: mémoire professionnel. IUFM Nord Pas-de-Calais: Villeneuve d'Asq, 2001.

Recebido em 28/02/2012

Aceito em 20/04/2012 